\title{
Site Matching Of Offshore Wind Turbines - A Case Study
}

\author{
Pravin B Dangar ${ }^{1}$, Santosh H Kaware ${ }^{2}$, Dr.P.K.Katti ${ }^{3}$ \\ Department of Electrical Engineering \\ Dr Babasaheb Ambedkar Technological University,Lonere,Raigad ,Maharashtra ,India \\ Corresponding author.Tel : $9867055282, E-m a i l:$ pravindangar@rediffmail.com,
}

\begin{abstract}
The stress on demand and supply gap of electricity has lead the globe to face acute problems. Further use of fossil fuel based energies for improved life and development have lead to adverse environmental effects, like climate change. Offshore wind farms have great potential as sustainable energy source. This accentuates to focus attention on technical issues such as selection, requirements, characteristics and power production from wind turbine. This paper presents a methodology developed for selection of optimum windmill for a specific site based on capacity factor approach by proper analysis of wind data. Offshore wind data for the purpose is obtained from, INCOIS Hyderabad- India for a particular site under proposal in India. The wind data is used to generate mean wind speeds for a typical day in a month by using MATLAB program. The windmill with the highest average capacity factor is the optimum one and to be recommended. The results of said analysis are presented. Such analysis at the planning and development stages of installation will enable the wind power developer or the power utilities to make a judicious choice of potential site and wind turbine generator system from the available potential sites and wind turbine generators respectively.
\end{abstract}

Keywords: Offshore wind, Climate change, Capacity factor, Wind data.

\section{Introduction}

A Number of potential wind power sites are available all over the world. Of these, not all sites have wind turbine generators installed. The observation with the existing wind farms shows that some of the wind power plants have performed poorly probably due to improper site matching. Hence there arises a $\mathrm{n}$ eed for a systematic approach toward the problem of optimum siting of wind turbine generators. [4] The production of electricity by a wind turbine generator at a specific site depends upon many factors. These factors include the mean wind speed of the site and the speed characteristics of the wind turbine itself namely, cut-in, rated, and furling wind speeds including the hub height. Commercially many models of wind turbine generators available, with similar MW and KW ratings. Each of these wind turbines has their own specifications and speed parameters. These speed parameters affect the capacity factor at a given specific site, and subsequently affect the choice of optimum wind turbine generator for the site. In this paper the method to determine capacity factor of different offshore wind turbine under different tower heights, rated wind speeds, is discussed for Mumbai offshore region.

\subsection{Capacity Factor}

It compares the plant's actual production over a given period of time with mean wind speed the amount of power the plant would have produced if it had run at rated wind speed for the same amount of time and hence can be defined as ;

$>$ The ratio of average power output to the rated power output [1]

$>$ An indicator of how much energy a particular wind turbine makes in a particular place.

C.F. $=(\mathrm{Pa} / \mathrm{Pr})$ 


\section{Methodology}

\subsection{Offshore Wind Turbine Site Matching Based On Capacity Factors}

The methodology for the selection of the optimum windmill for a specific site is developed the flowchart is shown in Fig 1. The selection is based on the capacity factors (CF) of the available windmills. The long term wind speed data recorded at different hours of the day for many years is used. The particular steps used to determine $\mathrm{C} \mathrm{F}$ for the mean wind speeds for at different hours of the day are generated with the manufacturer's specifications. The windmill with the highest capacity factor for the specific site is the optimum one and to be recommended.

\section{Step1: Calculation of Mean Wind Speeds}

The mean wind speed for a typical day of a month need to be generated by averaging all the recorded wind speeds for regular interval of long term data of the wind speeds for the site to be considered.

Methodology Of Determination Of Capacity Factor

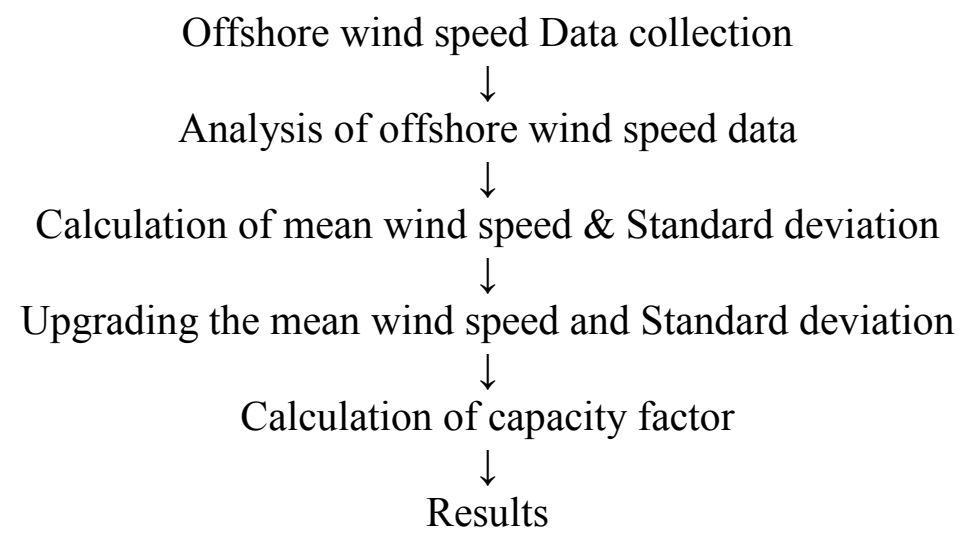

Fig 1 Methodology for determination of capacity factor

The mean wind speed is then calculated using the equation below

$V_{i}=\left(\frac{\sum_{j=1}^{N_{j}} V_{j}^{3}}{N_{j}}\right)^{1 / 3}$

Where

$\mathrm{V}_{\mathrm{j}}=$ observed wind speed

$\mathrm{N}_{\mathrm{j}}=$ number of wind speed observations

$\mathrm{V}_{\mathrm{i}}=$ mean wind speed

$>$ Step 2 Upgrading the Mean Wind Speed

$\mathrm{V}_{\mathrm{z}}=\mathrm{V}_{\mathrm{i}}\left(\frac{\mathrm{Z}}{\mathrm{Z}_{\mathrm{i}}}\right)^{\mathrm{x}}$

Where

$\mathrm{V}_{\mathrm{Z}}=$ mean wind speed at projected height, $\mathrm{Z}$ 
$\mathrm{V}_{\mathrm{i}}=$ mean wind speed at reference height, $\mathrm{Z}_{\mathrm{i}}$

$\mathrm{Z}=$ projected height (or hub height)

$\mathrm{x}=$ power law exponent depends upon the roughness of the surface. For open land, $\mathrm{x}$ is usually taken as $1 / 7$.

Step 3 Generation of the Wind Speed Probability Density Functions

$f(v)=\left(\frac{v}{C_{i}^{2}}\right) \exp \left(-\left(\frac{v}{2 C_{i}^{2}}\right)\right)$

Where

$\mathrm{C}_{\mathrm{i}}=\mathrm{v}_{\mathrm{i}} / 1.253$

$\mathrm{v}=$ wind speed

The Weibull probability density function is represented by

$$
f(v)=\left(\frac{k}{c}\right) \cdot\left(\frac{v}{c}\right)^{k-1} \exp \left(-\left(\frac{v}{c}\right)^{k}\right)
$$

Where;

$\mathrm{c}=$ scale factor, unit of speed

$\mathrm{k}=$ shape factor, dimensionless

$\mathrm{v}=$ wind speed

The Weibull parameters $\mathrm{c}$ and $\mathrm{k}$ can be found using the following acceptable approximations

$$
\begin{aligned}
& \mathrm{k}=\left(\frac{\sigma}{\mathrm{v}}\right)^{-1.086} \quad 1 \leq \mathrm{k} \leq 10 \\
& \mathrm{c}=\frac{\mathrm{v}}{\Gamma\left(1+\frac{1}{\mathrm{k}}\right)}
\end{aligned}
$$

In both the probability density functions, the wind speed $\mathrm{v}$ will be the mean wind speed $\mathrm{V}_{Z}$, calculated at hub height from equation (3)

\section{Step 4 Calculation of Capacity Factors}

The average power output from a wind turbine is the power produced at each wind speed multiplied by fraction of the time that wind speed is, experienced integrated over all possible wind speeds. In integral form the equation is $[2,4]$

$$
P_{a}=\int_{0}^{\infty} P_{w} \cdot f(v) \cdot d v
$$

Capacity factor can be defined as the ratio between average power output given by equation (6) and rated power of the wind turbine $\mathrm{P}_{\mathrm{r}}$ can be obtained from the manufacturer's details. In equation(6) the power at various wind speeds can obtained from the following equation 
$P_{w}=\left\{\begin{array}{cc}P \cdot \frac{v^{k}-v_{c}{ }^{k}}{v_{R}{ }^{k}-v_{c}{ }^{k}} & \text { for } v_{c} \leq v \leq v_{R} \\ P & \text { for } v_{R} \leq v \leq v_{f} \\ 0 & \text { elsewhere }\end{array}\right.$

Where

$\mathrm{P}$ is the rated electrical power,

$\mathrm{V}_{\mathrm{c}}$ is the cut in wind speed,

$\mathrm{V}_{\mathrm{R}}$ is the rated wind speed

$\mathrm{v}_{\mathrm{f}}$ is the cut off wind speed

$\mathrm{k}$ is the Weibull shape parameter defined under the equation(5), the relationship betweenpower and wind speed is as under,

$$
P=\frac{1}{2} C_{p} \cdot \rho \cdot A \cdot v^{3} \eta
$$

For which considering value of air density factor $\rho=3.485 \mathrm{P} / \mathrm{T}$

Where $\mathrm{P}=101.3 \mathrm{kpa}$ and $\mathrm{T}=273 \mathrm{~K}$ the power equation thus can be written as

$$
\mathrm{P}=0.646 \mathrm{C}_{\mathrm{p}} \cdot \mathrm{A} \cdot \mathrm{v}^{3} \cdot \eta
$$

Thus the capacity factor defined above can be expressed as

$$
C F=\frac{1}{P_{r}} \int P(v) \cdot f(v) \cdot d v
$$

Step 5 Choice of the Optimum Wind Turbine Based on Capacity Factor

The capacity factors of different turbines are computed from the wind speeds $\left(\mathrm{v}_{\mathrm{c}}, \mathrm{v}_{\mathrm{R}}, \mathrm{v}_{\mathrm{f}}\right)$ and rated power data obtained from manufacturer details. Now detailed table for the capacity factor for each turbine is prepared from which it can be clear that certain turbine will have a maximum value of capacity factor. This becomes the candidate which can produce the optimal power for the chosen site and wind data. $[4,5,6]$

\section{Computation and Results}

\subsection{Data Analysis:}

The wind speed data that is obtained from Indian National Centre for Ocean Information Services (INCOIS) has been first arranged on the hourly basis. The mean wind speed and standard deviation on the hourly basis and daily basis is computed. The results of computed mean wind speed data has been presented year wise for the year 1998 and 2005 respectively $i$ n Figure 2 to 5.

\subsection{Computation Of Capacity Factor}

The capacity factor of a machine indicates the ability to generate the mechanical energy by utilizing the wind power. This solely depends upon how the wind speed utilized to spin the rotor of turbine. The mean wind speed data that has been obtained from INCOISIS is used to determine the hub height wind speed as per the equation 3 . F urther wind turbine data of the 
selected machine is used for the computation of capacity factor for each of the machine the details of which are shown in table 1.the computation of capacity factor has been carried out by using MATLAB program.

Table 1. Offshore wind turbine specification

\begin{tabular}{ccccccc}
\hline Company Name & $\begin{array}{c}\text { Power } \\
\text { Rating } \\
\text { MW }\end{array}$ & $\begin{array}{c}\text { Cut in } \\
\text { wind } \\
\text { Speed } \\
(\mathrm{m} / \mathrm{s})\end{array}$ & $\begin{array}{c}\text { Rated } \\
\text { wind } \\
\text { speed } \\
(\mathrm{m} / \mathrm{s})\end{array}$ & $\begin{array}{c}\text { Cut out } \\
\text { wind } \\
\text { speed } \\
(\mathrm{m} / \mathrm{s})\end{array}$ & $\begin{array}{c}\text { Rotor } \\
\text { diameter in } \\
\text { meter }\end{array}$ & $\begin{array}{c}\text { Turbine Height } \\
\text { in meter }\end{array}$ \\
\hline RE Power & 5 & 3 & 11.4 & 25 & 126 & 90 \\
GE & 3.6 & 3.5 & 14 & 27 & 111 & 90 \\
Vestas & 3 & 3.5 & 15 & 25 & 90 & 90 \\
Vestas & 3 & 3 & 12 & 25 & 112 & 94 \\
\hline
\end{tabular}

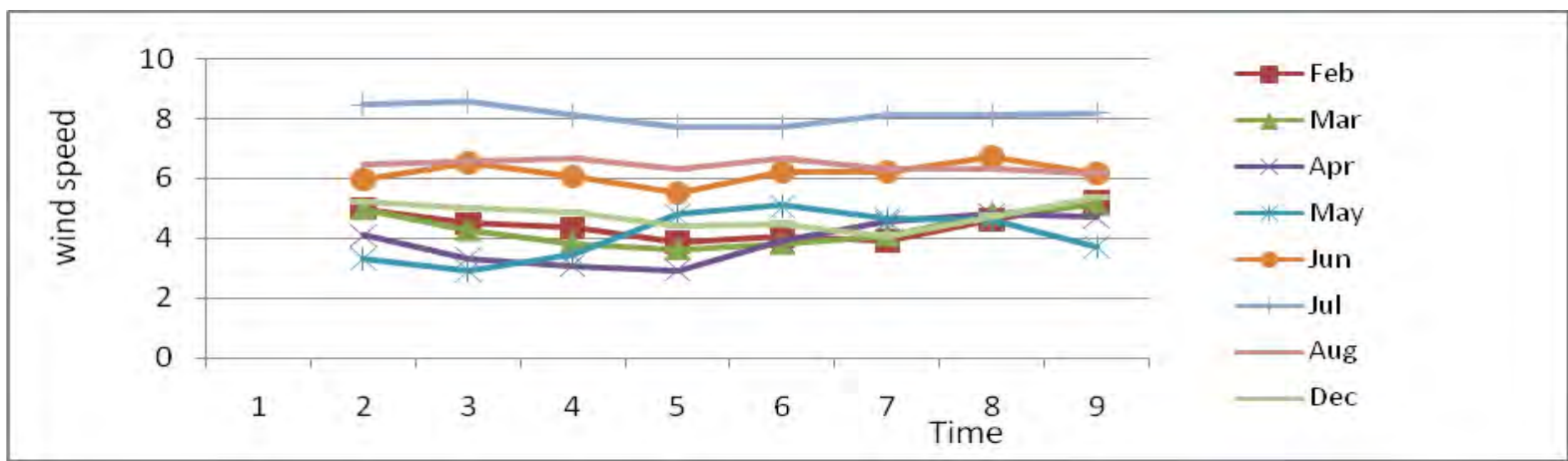

Fig .2 Hourly average mean wind speed of the year 1998

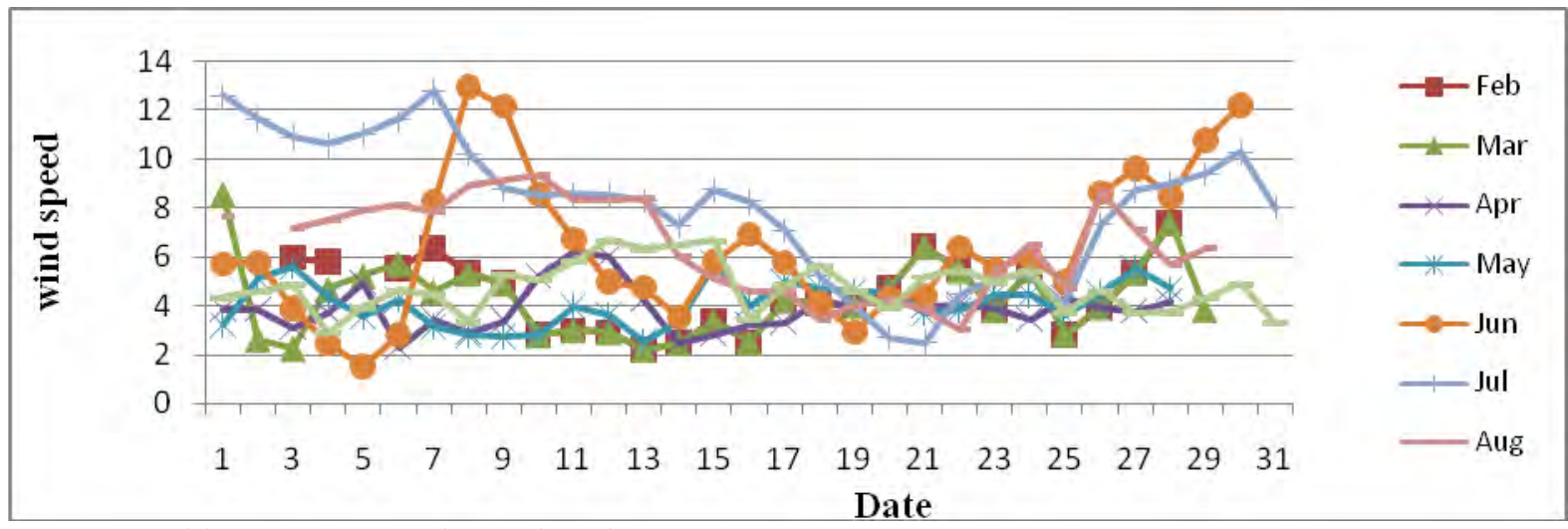

Fig 3 Monthly Average wind speed of the year 1998

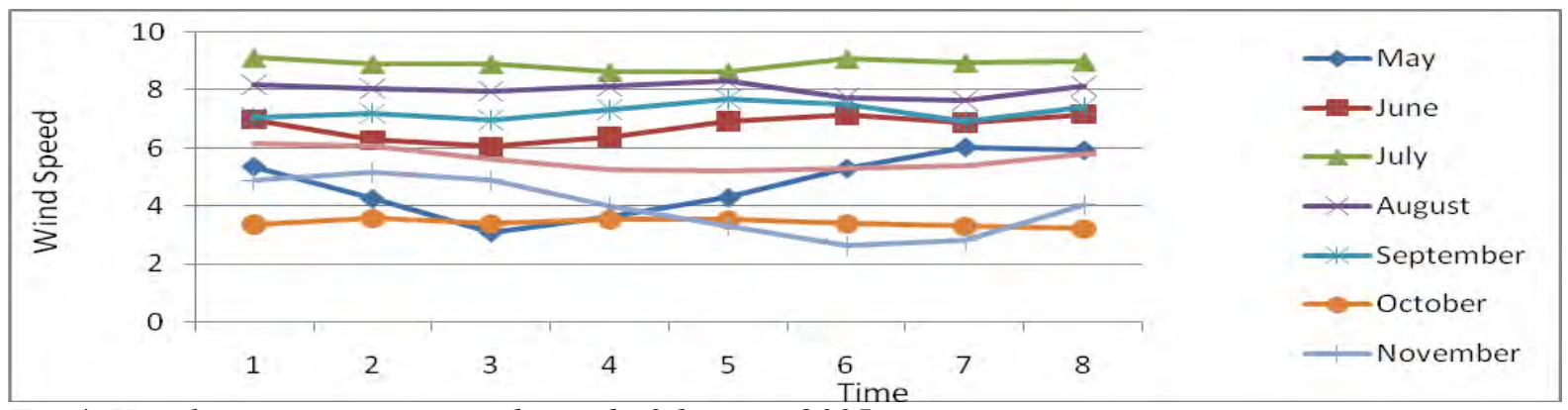

Fig.4. Hourly average mean wind speed of the year 2005 


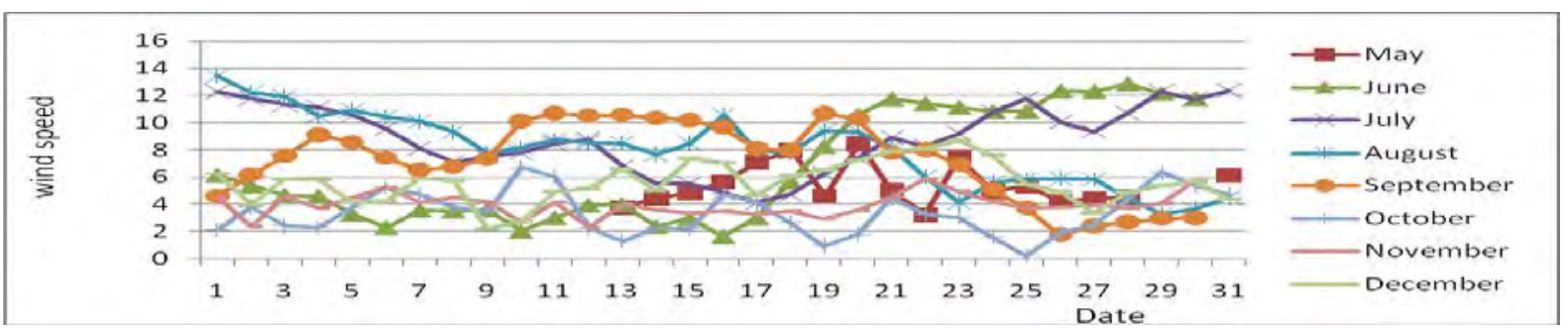

Fig .5. Monthly average wind speed of the year 2005

The graphical representation of monthly capacity factor for the selected machine for the respective years has been presented in Fig 6 and 7. Finally the annual capacity factors for the selected machine have been presented in tabular and graphically in table 2 and Fig.8. From the result available the machine with optimal capacity factor that is RE Power $5 \mathrm{MW}$ and Vestas 112/3.0 MW has been recommended.

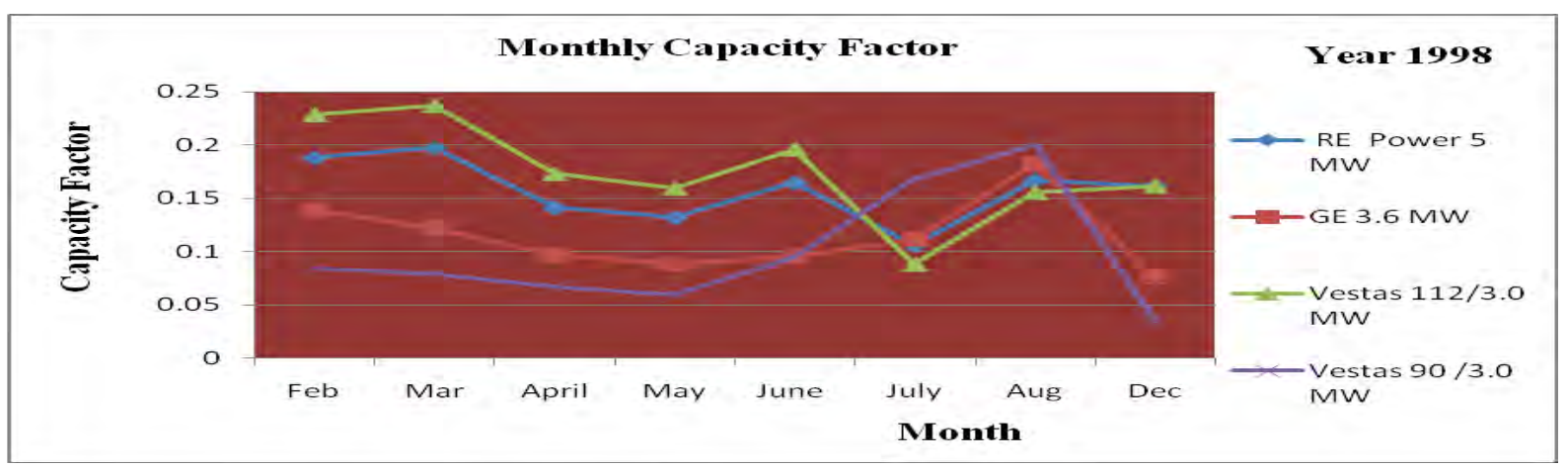

Fig.6. Monthly Capacity factor for the year 1998

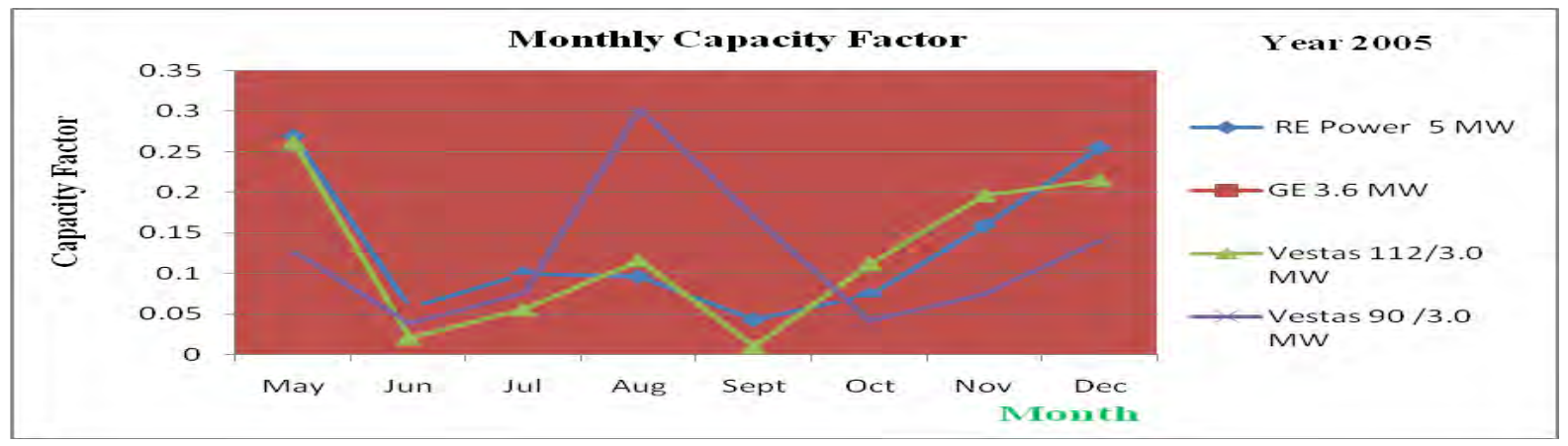

Fig.7. Monthly Capacity Factor for the year 2005

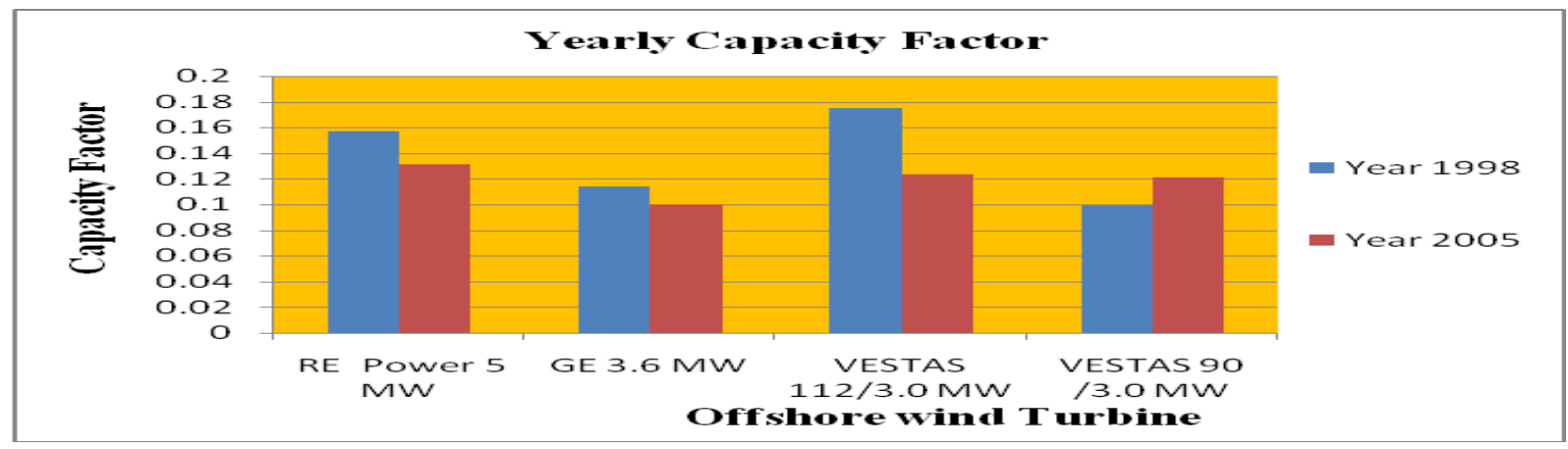

Fig. 8 Average annual capacity factor 
Table 2. Yearly average capacity factors

\begin{tabular}{|c|c|c|c|c|c|}
\hline \multicolumn{2}{|c|}{ Hub Height } & $90 \mathrm{~m}$ & $90 \mathrm{~m}$ & $94 \mathrm{~m}$ & $90 \mathrm{~m}$ \\
\hline Buoy ID & Year & $\begin{array}{l}\text { RE Power } \\
5 \mathrm{MW}\end{array}$ & $\begin{array}{c}\text { GE } \\
3.6 \mathrm{MW}\end{array}$ & $\begin{array}{c}\text { Vestas } \\
112 / 3.0 \mathrm{MW}\end{array}$ & $\begin{array}{c}\text { Vestas } \\
90 / 3.0 \mathrm{MW}\end{array}$ \\
\hline SWO2 & 1998 & 0.15727643 & 0.1142502 & 0.175344331 & 0.098867349 \\
\hline SWO2 & 2005 & 0.13160839 & 0.1001096 & 0.123371867 & 0.121234018 \\
\hline
\end{tabular}

The typical disposition of the selected wind turbines for the proposed site used in this work as mentioned has been presented in Fig. 9 and 10 respectively for RE power and Vestas machines. This will give an effective feel of how a wind form may appear if installed on an offshore site.

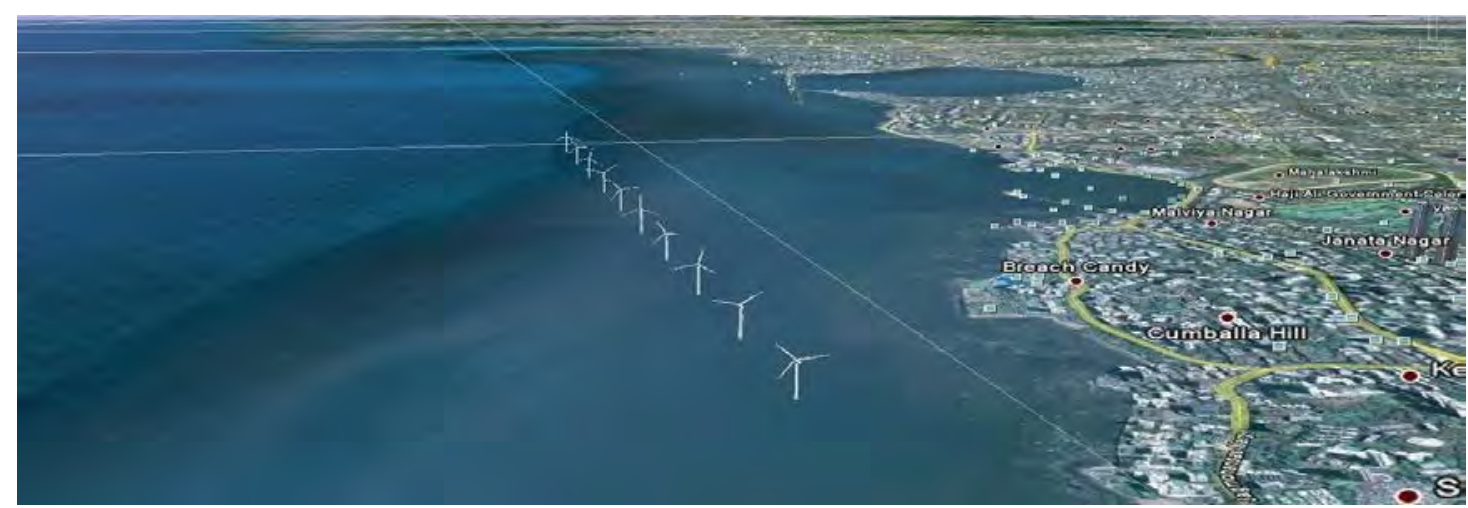

Fig.9. RE Power $5 \mathrm{MW}$ offshore wind turbine layout for 50MW

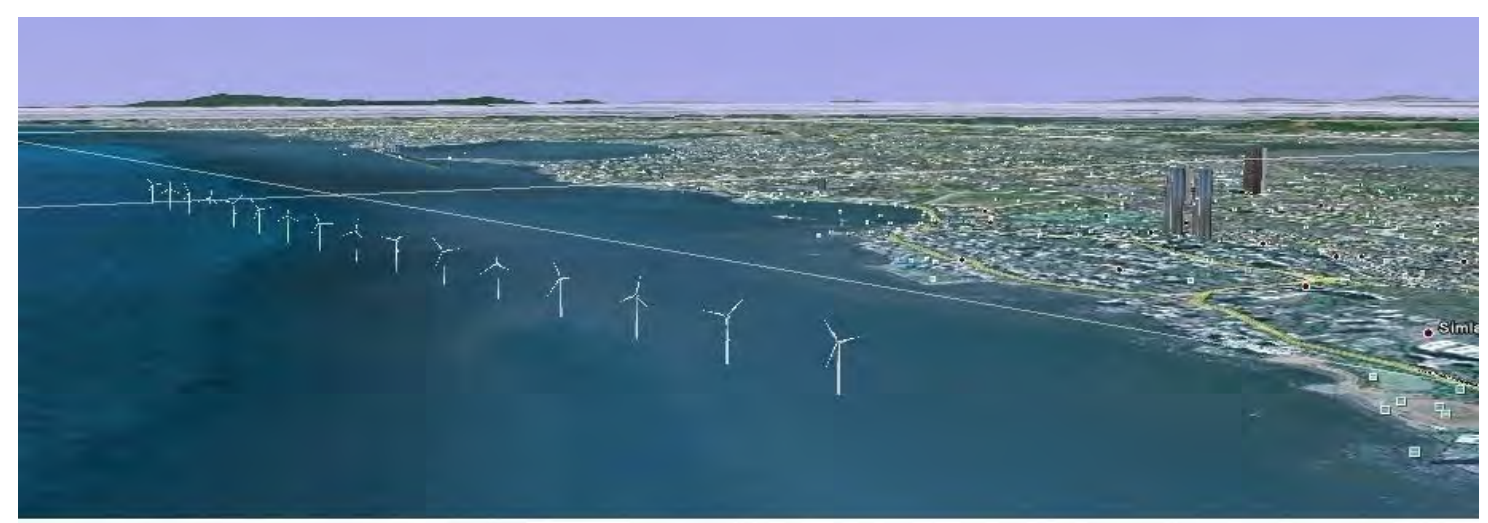

Fig.10. Vestas 112/3.0 MW offshore wind turbine layout for 50MW

\subsection{Conclusions}

The paper presents a methodology for assessment of offshore wind data and the capacity factor of wind turbines for their suitability to be used for harnessing offshore wind energy in a better fashion as depicted by the results. This not only helps to choose a better turbine but also to maximize the system performance. Further the illustration presented for a specific site in Konkan region of Maharashtra exemplifies the suitability of method presented. 


\section{Acknowledgement}

The authors acknowledge thankfully the support extended by Indian National Centre for Ocean Information Services,(INCOIS) Hyderabad for providing necessary offshore wind data for Mumbai (India) offshore area, Department of Electrical Engineering, and Dr. Babasaheb Ambedkar Technological University, Lonere, Dist: Raigad, Maharashtra (India) for their financial support during the work.

\section{References}

[1] Jeffrey Logan and Stan Mark Kaplan Wind Power in the United States: Technology, Economic, and Policy Issues June 20, 2008 Specialists in Energy Policy Resources, Science, and Industry Division. pp 1-53

[2] Pradeep.K.Katti, Dr.Mohan K Khedkar, Generation capacity Assessment of Distribute Resources Based on Weather Model for Integrated Operation, International conference CERA -2005, IIT Roorke India . pp1-6

[3] Ziyad M. Salameh lrianto Safari, Optimum Windmill- Site Matching . IEEE Transactions on Energy Conversion, Vol. 7, No. 4, December 1992. pp 669-676

[4] Suresh H. Jangamshetti, and V. Guruprasada Rau, Optimum Siting Of Wind Turbine Generators , IEEE Transactions on Energy Conversion, Vol 16, No. 1, March 2001,pp 8-13

[5] Tai-Her Yeh and Li Wang A Study on Generator Capacity for Wind Turbines Under Various Tower Heights and Rated Wind Speeds Using Weibull Distribution , IEEE Transactions on Energy Conversion, Vol. 23, No. 2, June 2008,pp-592-602

[6] Suresh H. Jangamshetti, and Dr. V. Guruprasada Rau, Site matching of wind turbine Generators : A case study, IEEE Transactions on Energy Conversion, Vol. 14, N o. 4, December 1999 pp- 1537-1543

[7] Bogdas S.Borowy,Ziyad M Salame Methodology for Optimally Sizing the Combination of a Battery Bank and PV Array in a Wind/PV Hybrid System IEEE Transactions on Energy Conversion, Vol. 11, No. 2, June 1996 pp 367-375 